\title{
ECG Test Results Evaluation Interval
}

National Cancer Institute

\section{Source}

National Cancer Institute. ECG Test Results Evaluation Interval. NCI Thesaurus. Code C119823.

The period of time during which an electrocardiogram was performed. 